\title{
Lying Because We Care: \\ Compassion Increases Prosocial Lying
}

\section{Supplemental Material \\ Study 1}

Table 1a: Regression table for the effect of compassion on prosocial lying, controlling for positive affect, negative affect, personal distress, specific emotions, and social perceptions.

Dependent variable:

Overall Evaluations

(1) (2) (3)

(4)

\begin{tabular}{|c|c|c|c|c|}
\hline Condition: compassion & $\begin{array}{c}-4.482^{* * *} \\
(1.610)\end{array}$ & $\begin{array}{l}-3.916^{* * *} \\
(1.765)\end{array}$ & $\begin{array}{c}-5.517^{* * * *} \\
(1.456)\end{array}$ & $\begin{array}{c}-5.817^{* * * *} \\
(1.515)\end{array}$ \\
\hline Time: shared & $\begin{array}{c}-0.723 \\
(1.569)\end{array}$ & $\begin{array}{c}-0.160 \\
(1.720)\end{array}$ & $\begin{array}{l}-2.623 \\
(2.268)\end{array}$ & $\begin{array}{l}-4.111 \\
(2.547)\end{array}$ \\
\hline Positive affect & $\begin{array}{c}6.146^{* * *} \\
(1.544)\end{array}$ & & & $\begin{array}{c}1.872 \\
(1.399)\end{array}$ \\
\hline Negative affect & $\begin{array}{l}-5.905 \\
(4.076)\end{array}$ & & & $\begin{array}{c}0.004 \\
(3.608)\end{array}$ \\
\hline Personal distress & $\begin{array}{l}5.495^{*} \\
(3.050)\end{array}$ & & & $\begin{array}{c}0.059 \\
(2.689)\end{array}$ \\
\hline Interested & & $\begin{array}{c}0.934 \\
(0.860)\end{array}$ & & \\
\hline Distressed & & $\begin{array}{c}0.789 \\
(1.061)\end{array}$ & & \\
\hline Excited & & 1.211 & & \\
\hline
\end{tabular}


(1.638)

Upset

0.666

(0.903)

Strong

$-1.276$

(1.049)

Guilty

0.196

(1.192)

Scared

$-1.256$

(2.025)

Hostile

2.391

(1.808)

Enthusiastic

$2.707^{*}$

(1.608)

Proud

$-0.665$

(1.410)

Irritable

$-1.922^{*}$

(1.025)

Alert

$-1.711^{*}$

(0.911)

Ashamed

$-3.155^{* * *}$

(1.210)

Inspired

$2.536^{* *}$

(1.217)

Determined

0.039

(1.286)

Nervous

$3.064^{*}$

(1.672) 
Attentive

$-0.995$

(0.811)

Jittery

1.436

(1.578)

Active

$1.968^{*}$

(1.188)

Afraid

0.996

(1.782)

Optimistic

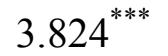

$3.711^{* * *}$

(0.591)

(0.593)

Warm

$\begin{array}{ll}-0.121 & -0.073 \\ (0.699) & (0.697)\end{array}$

Agreeable

0.173

0.098

(0.756)

(0.753)

Competent

$\begin{array}{ll}1.817^{* *} & 1.738^{* *} \\ (0.815) & (0.819)\end{array}$

Open

$\begin{array}{ll}-0.111 & -0.189 \\ (0.601) & (0.600)\end{array}$

Likeable

$\begin{array}{cc}0.349 & 0.291 \\ (0.839) & (0.843)\end{array}$

Trusting

$\begin{array}{ll}-0.082 & -0.035\end{array}$

(0.767) (0.767)

Trustworthy

$\begin{array}{ll}2.117^{* *} & 2.075^{* *} \\ (0.826) & (0.824)\end{array}$

Likely to be female

$-0.955^{*} \quad-0.888$

(0.567) (0.567) 
Condition: compassion*time: shared

Time: shared*positive affect

Time: shared*negative affect

$-3.243$

Time: shared*personal distress

$3.879^{* *}$

Time: shared*interested

Time: shared*distressed

Time: shared*excited

Time: shared*upset

Time: shared*strong

Time: shared*guilty

Time: shared*scared

Time: shared*hostile

Time: shared*enthusiastic

$\begin{array}{lll}2.003^{*} & 3.734^{* * *} & 2.787^{* * *} \\ (1.054) & (0.987) & (1.023)\end{array}$

$1.856^{* *}$

(0.944)

$-3.845$

(2.436)

$4.071^{* *}$

(1.815) 
(0.961)

Time: shared*proud

0.214

(0.842)

Time: shared*irritable

0.524

(0.612)

Time: shared*alert

0.221

(0.544)

Time: shared*ashamed

$-0.346$

$(0.723)$

Time: shared*inspired

0.243

(0.727)

Time: shared*determined

0.979

(0.768)

Time: shared*nervous

0.405

(0.999)

Time: shared*attentive

$-0.072$

(0.484)

Time: shared*jittery

$-1.408$

(0.943)

Time: shared*active

0.422

(0.710)

Time: shared*afraid

0.079

(1.064)

Time: shared*optimistic

$-0.485$

$-0.622$

(0.400)

(0.400)

Time: shared*warm

0.547

0.574

(0.474)

(0.471) 
Time: shared*agreeable

Time: shared*competent

Time: shared*open

Time: shared*likeable

Time: shared*trusting

Time: shared*trustworthy

Time: shared*likely to be female

Constant
0.161

0.215

(0.553)

$-0.617$

(0.408)

0.225

(0.569)

$-0.237$

(0.520)

0.881

$(0.560)$

$0.645^{*}$

(0.384)

$18.984^{* * *}$

(2.695)
$18.680^{* * *}$

(2.878)
0.107

(0.508)

$-0.038$

(0.553)

$-0.658$

(0.405)

0.140

(0.569)

$-0.154$

(0.518)

0.837

(0.557)

$0.783^{* *}$

(0.383)

2.653

(3.773)
Observations

Log Likelihood

Akaike Inf. Crit.

Bayesian Inf. Crit.
792

$-3,017.998$

792

792

792

$6,059.997$

$-2,959.015$

$-2,953.394$

$-2,936.081$

$6,116.092$

$5,954.789$

$5,932.163$

Note: Positive affect items: interested, excited, strong, enthusiastic, proud, alert, inspired, determined, attentive, active; negative affect: distressed, upset, guilty, scared, hostile, irritable, ashamed, nervous, jittery, afraid; personal distress: distressed, upset, scared, nervous, afraid. Items to measure social perceptions of essay writer: optimistic, warm, agreeable, competent, 
likeable, trusting, trustworthy, likely to be female. See main text for full description of items. ${ }^{*} \mathrm{p}$ $<.10 ;{ }^{* *} \mathrm{p}<.05 ;{ }^{* * *} \mathrm{p}<0.01$

\section{Study 3}

\section{Paragraph about the charity shown to participants in the Prosocial Lie condition in Study} 3

The AMF [Against Malaria Foundation] provides long-lasting insecticide-treated nets and has them distributed in developing countries to prevent malaria, a disease that kills over a million people a year. Insecticide-treated bed nets prevent deaths and many other non-fatal cases of malaria and are relatively inexpensive. AMF has been chosen as the \#1 most effective charity in the world by GiveWell, a non-profit organization that conducts in-depth research aimed to determine how much good a given charity accomplishes (in terms of lives saved, lives improved, etc.) per dollar spent.

Table 2a: Regression table for the effect of compassion on clearly dishonest responses, controlling for positive affect, negative affect, personal distress, and personality traits.

Dependent variable:

Clearly Dishonest Responses

(1)

(2)

(3)

Condition: compassion

$9.139^{* *}$

16.087

$7.901^{*}$

$8.836^{*}$

(n)


Negative affect

2.373

(8.557)

Personal distress

$-4.445$

(7.493)

Interested

Distressed

Excited

Upset

Strong

Guilty

Scared

Hostile

Enthusiastic

Proud

Irritable
3.813

(9.150)

$-5.243$

(8.097) 
Alert

$-1.645$

(2.424)

Ashamed

1.203

(3.367)

Inspired

$-0.733$

(2.632)

Determined

0.881

(2.273)

Nervous

4.879

(3.482)

Attentive

0.451

(2.138)

Jittery

$-2.187$

(2.690)

Active

1.456

(3.066)

Afraid

2.179

(4.025)

Conscientiousness

Neuroticism

$-2.238$

$-2.426$

(3.199)

(3.300)

Openness

$\begin{array}{ll}-3.351 & -4.224 \\ (6.013) & (6.241)\end{array}$

Extraversion

2.176

0.919 
Agreeableness

Constant

$57.053^{* * *}$

$58.142^{* * *}$

56.069

$63.061^{*}$

(5.308)

(6.366)

(35.887)

(37.165)

Observations

134

134

132

132

$\mathrm{R}^{2}$

0.038

0.153

0.045

0.051

Adjusted $\mathrm{R}^{2}$

0.009

$-0.006$

$-0.001$

$-0.019$

Residual Std. Error

$21.361(\mathrm{df}=129)$

$21.516(d f=112)$

$21.539(\mathrm{df}=$

125)

$21.730(\mathrm{df}=$ 122)

F Statistic

$$
\begin{array}{cc}
1.290(\mathrm{df}= & 0.963(\mathrm{df}= \\
4 ; 129) & 21 ; 112)
\end{array}
$$

$0.977(\mathrm{df}=$ $6 ; 125)$

$0.731(\mathrm{df}=$ 9;122)

Note: Positive affect items, negative affect items, and personal distress predictors are the same as those in Table 1a. Big 5 personality traits are conscientiousness, neuroticism, openness, extraversion, and agreeableness. Models that included personality traits have two less observations due to a computer malfunction that resulted in missing data for those variables for two responses. ${ }^{*} \mathrm{p}<.10,{ }^{* *} \mathrm{p}<.05,{ }^{* * *} \mathrm{p}<0.01$.

Table 3a: Regression table for the effect of compassion on ambiguously dishonest responses, controlling for positive affect, negative affect, personal distress, and personality traits.

Dependent variable:

Ambiguously Dishonest Responses

(1)

(2)

(3)

(4)

Condition: compassion

$10.234^{* * *}$

$16.222^{*}$

$8.081^{* *}$

$10.046^{* *}$


(3.860)

(5.134)

(3.298)

(3.970)

Positive affect

3.228

Negative affect

1.065

(7.396)

$-4.950$

(6.476)

Interested

Distressed

Excited

Upset

Strong

Guilty

Scared

Hostile

Enthusiastic

Proud
3.398

(3.066)

2.081

(7.889)

$-5.309$

(6.981)
0.408

(2.258)

1.656

(2.424)

0.046

(3.402)

$-4.476^{*}$

(2.483)

2.163

(2.419)

$-1.129$

(2.781)

$-5.120$

(3.118)

1.205

(2.412)

$-3.503$

(2.641)

3.306 
Irritable

1.254

(1.826)

Alert

$-1.879$

(2.095)

Ashamed

0.772

(2.911)

Inspired

$-1.594$

(2.275)

Determined

0.692

(1.965)

Nervous

4.380

(3.010)

Attentive

0.709

(1.848)

Jittery

$-1.106$

(2.326)

Active

1.717

(2.650)

Afraid

0.963

(3.480)

Conscientiousness

5.261

(6.214)

5.441

(6.244)

Neuroticism

$-2.486$

$-2.459$

(2.773)

(2.845)

Openness
$-2.759$

(5.212)

\section{$(2.845)$}

$-3.679$

(5.381) 
Extraversion

Constant $60.694^{* * *}$

$59.645^{* * *}$

$56.625^{*}$

$65.202^{* *}$

Observations

$\mathrm{R}^{2}$

Adjusted $\mathrm{R}^{2}$

Residual Std. Error

F Statistic

134

0.060

0.031

$18.463(\mathrm{df}=129)$

$18.599(\mathrm{df}=112)$

$$
2.067^{*}(\mathrm{df}=
$$

$4 ; 129)$

134

0.172

0.017

$1.108(\mathrm{df}=$ $21 ; 112)$
132

0.061

0.016

$18.669(\mathrm{df}=$ 125)

132

0.077

0.009

$18.735(\mathrm{df}=$ 122) $1.362(\mathrm{df}=$ $6 ; 125)$ $1.137(\mathrm{df}=$ $9 ; 122)$

Note: All predictors are the same as those in Table 2a. Models that included personality traits have two less observations due to a computer malfunction that resulted in missing data for those variables for two responses. ${ }^{*} \mathrm{p}<.10,{ }^{* *} \mathrm{p}<.05,{ }^{* * *} \mathrm{p}<0.01$.

\section{Results with Block Included as a Factor}

For each dependent variable (clearly dishonest responses, ambiguously dishonest

responses, honest responses), we conducted a 2 (Emotion: compassion vs. neutral) x 2 (Lie Type: prosocial vs. selfish) x 2 (Block: first vs. second) mixed-model ANOVA with repeated measures on the block factor. Although we did not have a priori expectations about interactions between block and either emotion or lie type, we included block as a factor given the possibility that dishonesty would increase in the second block due to fatigue or depleted self-control (e.g. Mead, Baumeister, Gino, Schweitzer, \& Ariely, 2009). 
For clearly dishonest responses, there was a significant Emotion x Lie Type interaction, $F(1,428)=6.51, p=.01, \eta_{\mathrm{p}}^{2}=.01$. Participants in the compassion condition $(M=63.61, S D=$ 23.60) exhibited significantly more prosocial lying than did those in the neutral condition $(M=$ $57.66, S D=19.16), t(212)=2.03, p=.04, d=.28), t(212)=2.03, p=.04, d=.28$. There was not a statistically significant difference between selfish lying in the compassion condition ( $M=$ $53.79, S D=19.18)$ versus in the neutral condition $(M=57.91, S D=19.78), p=.12$. While there was no main effect of emotion on lying $(p=.66)$, there was a significant main effect of lie type, $F(1,428)=5.28, p=.02, \eta_{\mathrm{p}}^{2}=.01$, such that participants engaged in more lying in the prosocial lie conditions $(M=60.52, S D=21.56)$ than in the selfish lie conditions $(M=56.00$, $S D=19.57)$. There were no other main effects or interactions $(p s>.40)$

Similar results were obtained for ambiguously dishonest responses. There was again a significant Emotion $\mathrm{x}$ Lie Type interaction, $F(1,428)=5.96, p=.02, \eta_{\mathrm{p}}^{2}=.01$. Those in the compassion condition $(M=66.78, S D=20.29)$ exhibited significantly more prosocial lying than did those in the neutral condition $(M=60.89, S D=16.26), t(212)=2.35, p=.02, d=.32$. There was not a statistically significant difference between selfish lying in the compassion condition $(M=58.83, S D=16.39)$ versus in the neutral condition $(M=61.26, S D=17.54), p>.25$. There was no main effect of emotion condition on lying $(p>.25)$, but there was a significant main effect of lie type, $F(1,428)=4.45, p=.04, \eta_{\mathrm{p}}^{2}=.01$, such that participants engaged in more lying in the prosocial lie condition $(M=63.72, S D=18.50)$ than in the selfish lie condition $(M=$ $60.14, S D=17.02)$. Additionally, there was a main effect of block, $F(1,428)=4.56, p=.03, \eta_{\mathrm{p}}^{2}$ $=.01$, such that participants engaged in more prosocial lying in the second block than in the first $(M=62.43, S D=18.89)$ than in the second $(M=61.40, S D=18.17)$. There were no other significant main effects or interactions $(p \mathrm{~s}>.50)$. 
Finally, we examined honest responses. As predicted, there was no significant Emotion $\mathrm{x}$ Lie Type interaction, $(p=.29)$. There were also no main effects of induction, lie type, or block on honest responses $(p s>.10)$. There was a marginally significant Emotion $\mathrm{x}$ Block interaction $(F(1$, $\left.428)=3.10 ; p=.08, \eta_{\mathrm{p}}^{2}=.01\right)$, such those in the compassion condition $(M=78.92, S D=15.23)$ exhibited less honest responses than those in the neutral condition $(M=79.19, S D=12.55)$ in the

first block, but more honest responses in the second block $\left(M_{\text {second }}=80.05, S D_{\text {second }}=14.12 \mathrm{vs}\right.$. $M_{\text {first }}=78.34, S D_{\text {first }}=13.62$ ). However, neither of these differences reached statistical significance $(p s>.20)$.

\section{$\underline{\text { References }}$}

Mead, N. L., Baumeister, R. F., Gino, F., Schweitzer, M. E., \& Ariely, D. (2009). Too tired to tell the truth: Self-control resource depletion and dishonesty. Journal of Experimental Social psychology, 45(3), 594-597. 